\title{
IMPRESSIONS OF ANTI-VENEREAL MEASURES, SO FAR AS WOMEN AND CHILDREN ARE CONCERNED, IN CERTAIN SCANDINAVIAN COUNTRIES AND HOLLAND (JULY, I 937)*
}

By MARGARET RORKE, M.B., Сн.B., M.C.O.G.

THose who have read the Commission's report and those who have just had the pleasure of hearing Colonel Harrison give a summary of the principal features must realise that it only remains for me as a member of the Commission to give a few notes on the measures so far as they affect women and children.

May I begin by assuring you that in the nineteen days which our visit occupied, we were very diligent in our search for information.

What struck me most from the women's point of view?

Well, first of all the brightness of nearly all of the clinics. It was July-sunny and warm, and probably everything looked at its best. But some things were not dependent on the weather - the hanging flowering plants, the benches enamelled white; in some polyclinics the modernity of the waiting-room-one of them looked more like a lounge in some young married people's country cottage than a clinic waiting-room!

Then as to the people. I was tremendously impressed by most of the women doctors I saw-they were really fine people-efficient, friendly and kindly. The secretaries and nurses in the clinics and hospitals also were extremely well educated and charmingly-mannered : one would be surprised if patients did not want to attend such pleasant polyclinics.

In the women's polyclinics (as opposed to hospital clinics) one thing struck me-the youth of the outpatients. Offhand, I can only remember three middle-

* Based on an address to the Medical Society for the Study of Venereal Diseases, November $24^{\text {th }}$, $193^{8}$. 
aged women sitting in all the out-patients put together. The rest appeared to be the age of maximum infectivity in this country, seventeen to twenty-two years old. I did not discover the reason for the dearth of older women patients. Perhaps some attend a purely medical department, with later lesions. What of the older women suffering from gonorrhœa? Where do they attend ?-or is it that they are not infected?

You have been told of the great uniformity of instruction in the treatment of venereal diseases in each of the Scandinavian countries, and this seems to be a strong factor in maintaining attendances, since no doctor will give advice materially differing from that given by any other doctor in the country.

Treatment of syphilis seems to have been very thorough in each country, as may be judged by the Official Report and by Colonel Harrison's paper. Infected women are always told to report for injections in each subsequent pregnancy, and seem to do so to such an admirable extent that infantile and childish congenital syphilis is becoming very rare. One could not discover that there was any general routine taking of blood for W.R. during pregnancy: so that the attendance of these women is evidently due to their strong sense of duty and to their admirable discipline- a cheerful discipline, be it understood. In the clinics I saw, the women " jumped to it" cheerfully and happily. An eye was kept on the door, and the next patient went in the moment the light above the door showed that the doctor was free: and another patient immediately took her place in a chair at the door, ready for the next light signal.

As a result of good ante-natal treatment the numbers of congenital syphilis in all countries in Scandinavia are falling swiftly! Consequently the Welander Homes for congenital syphilitic children are now far from full. In Stockholm we saw one such Home, in size, spirit and decoration reminiscent of Dr. Brown's Waddon Home here for Vulvo-vaginitis. This Home was meant for fifty children, and originally took this number-now only twenty were in residence. These children all had now or at one time a positive serological reaction for syphilis, but none that we saw had any gross stigmata. There were charming rooms with bright curtains and vividly painted furniture, toys, a garden : and very intelligent 
and extremely keen nurses in charge. The children stay there about three years, and have various courses of injections ordered by the Medical Staff of Professor Strandberg's Clinic at St. Gören's Hospital, Stockholm.

Gonorrhoea in Women.-While we were in Scandinavia there was no talk of sulphonamide treatment anywhere. The treatment of women seemed to be local only, and oral medication was given only in the cases which were complicated. In various hospitals we saw beds occupied by young women with acute salpingitis-treatment seemed to be mainly expectant-occasionally vaccines were given. It was said in Sweden that if young girls (hitherto respectable) acquired acute gonorrhœa, there was a feeling that they were better as hospital bed cases, both for treatment and to keep them away from bad companions. They said that the same might be done in the case of a young man too; we had no means of checking up on what percentage were so dealt with.

Tests of cure were by means of repeated films from urethra and cervix, especially after a period. Cultures were very rarely done and never in the outside polyclinics. The gonococcal C.F.T. was rarely done save in some hospital clinics, and in some of these a blood sedimentation test was done instead.

At the time of our visit in July, 1937, we found no evidence that the anti-venereal measures had had any important effect on the incidence of gonorrhœa. It will be interesting to see if sulphonamide treatment, which is now, doubtless, in general use, effects any change in this respect.

Treatment then seemed very simple, but tests of cure must have been good, as we were given to understand that ophthalmia neonatorum was almost unknown.

There are no V.D. Hospital almoners in Scandinavian countries.

In investigation of contacts, a women is more likely to know the name of her consort. A man, especially a stranger or a foreigner, may not know the name of a girl. In Sweden, if known, such person can be compelled to attend for examination. In Denmark there was not, in I937, legal power to enforce this attendance of the consort, but the desirability of legislation to this effect was being discussed.

In Copenhagen a girl would be traced by a " Night Patrol " of police, who went particularly to low class 
cafés frequented by sailors, labourers, etc.; they also ask any women who seem to be street-walking what their occupation is, and if they cannot prove a gainful occupation other than prostitution they are taken up at once for medical examination. If free from infection and if they have no paid work in about five or six weeks, the police would then consider them prostitutes and vagabonds and would then put them in prison. On inquiring if there really was work for them, I was told that at present there was lots of work to be had in factories.

Although from the public health point of view, this system of requiring proof that a woman is properly employed must be helpful, in that infected persons are bound to be treated, yet to the English mind there was an unhappy feeling that injustice might be done to some young women in this way.

A small but interesting point which I elicited was that almost all prostitutes in Denmark were Danes : the small minority remaining were from other Scandinavian countries. There were said to be no English, French or German girls practising prostitution in Copenhagen, which was a little surprising. I tried to see a rescue home for young girls, but the matron did not find it convenient to receive me on the only day that I had a little free time.

Only in one place in Denmark did we hear of unemployment - that was in Odense, where there was said to be a good deal of unemployment in the textile electrical supplies, and jam-jar factories. There were no slums seen by any of us in Scandinavia and none of the poverty or the beggars which are to be seen in our English great cities. Although there are no doubt some very wealthy people in Scandinavia, the difference in the classes seemed much less marked than here, and housing and nutrition at a much higher level for the poorer classes. This undoubtedly greatly enhances self-respect, and should such a person acquire a venereal disease, he would naturally think it well worth while to persevere in treatment, until clean and free from disease.

Of the new cases, the overwhelming majority were gonorrhœa-the incidence of new syphilis was very greatly diminished : most of the new cases were sailors, we were told. Sailors also accounted for a certain percentage of lapsed cases, as of necessity they had to return to sea when their acute infection was over. But in each 
hospital visited a high proportion of male patients were sailors.

\section{HOLLAND}

Holland was chosen for study as a contrast country where notification of venereal disease was not in force, because it was a thriving and a normal country and considered to be suitable for comparison in respect of venereal diseases with the Scandinavian countries visited, which it resembles in many respects.

Owing to the time necessarily spent on investigation of conditions in the three Scandinavian countries visited, we had only three clear days in Holland. But here, as in Scandinavia, the kind and willing co-operation of State officials and clinic doctors alike, enabled us to spend the time to excellent purpose.

We were told, and it was proved statistically, that the incidence of new primary and secondary syphilis in Holland had fallen rapidly. Recently there had been an epidemic of early syphilis in a small village ; on careful investigation it was found to be due to the visit there of a prostitute from a large town. When this was dealt with and intensive treatment begun, there was no extension of the outbreak.

We were told that compulsion in any form was abhorrent to the spirit of the Dutch people. That in the Netherlands there was no compulsory notification of tuberculosis, and therefore definitely not of venereal disease. Many interesting social questions were opened up by facts learned at the Hague-e.g., that there was a very low incidence of ophthalmia neonatorum, and of arthritis, and that the illegitimacy birthrate had slowly fallen and was in I937 only about 2,000 per annum; total births were about 165 , 000 per annum. This was a favourable illegitimacy birthrate by comparison with the other countries visited.

It was interesting to hear at the Hague that Dutch propaganda against venereal disease was very discreet and that the words "venereal disease" would never be mentioned in a newspaper.

The main venereal disease clinics were in Rotterdam and in Amsterdam-sometimes as purely venereal and dermatological clinics and sometimes as part of the polyclinics of general hospitals. 
In Rotterdam there are special V.D. clinics near the docks, and graphs there showed a great fall in the incidence of early syphilis in recent years. In the Rotterdam Municipal Hospital there were forty beds for skin and venereal diseases.

In the Netherlands there seemed to be an extremely good " follow-up " by trained nurses of great discretion. So well was this done that "the majority" of lapsed patients were said to return. In Rotterdam there were two such workers, in the Hague one social worker, etc.

In Amsterdam one rather odd and disconcerting piece of information was received-that for the past eight or ten years there had been more than 200 cases of gonococcal vulvo-vaginitis in children annually.

In Amsterdam we were told that there were plenty of beds for V.D. and for all infectious diseases; that there were no isolation hospitals, but that all diseases were treated in the large general hospitals, though infectious diseases were in separate blocks, and this must make for economy in management.

It was said in Amsterdam that follow-up in the case of lapsed married people was rather difficult ; that there was no difficulty in getting married women to attend for treatment of syphilis; but that they were " too busy" to keep attending for treatment of gonorrhœa. Here, as in Scandinavia, in July, I937, no sulphonamide medication was in use, and the lapsing of married women patients suffering from gonorrhœea has no doubt a definite connection with the number of children quoted as suffering from gonococcal vulvo-vaginitis.

Funds were raised for the treatment of venereal disease in Holland partly by Government grant and partly by voluntary effort in various parts of the Netherlands by some of the many "Cross" Societies responsible for public health-“"Yellow Cross," etc., taking part in all health matters in a particular province; treatment of venereal disease was by specialists.

Altogether it seemed to us that each country had the method of treatment-i.e., compulsory or voluntarythat suited its national characteristics, and that in the Scandinavian countries visited the fact that "necessity for treatment " was put forcibly before " health-conscious" people was a paramount factor in their co-operation and willingness to take treatment. 